\title{
The complex neurobiology of resilient functioning after childhood maltreatment
}

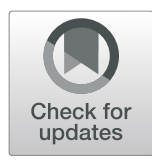

\author{
Konstantinos loannidis ${ }^{1,2^{*}}$, Adrian Dahl Askelund ${ }^{1}$, Rogier A. Kievit ${ }^{3}$ and Anne-Laura van Harmelen ${ }^{1^{*}}$ (D)
}

\begin{abstract}
Background: Childhood maltreatment has been associated with significant impairment in social, emotional and behavioural functioning later in life. Nevertheless, some individuals who have experienced childhood maltreatment function better than expected given their circumstances.

Main body: Here, we provide an integrated understanding of the complex, interrelated mechanisms that facilitate such individual resilient functioning after childhood maltreatment. We aim to show that resilient functioning is not facilitated by any single 'resilience biomarker'. Rather, resilient functioning after childhood maltreatment is a product of complex processes and influences across multiple levels, ranging from 'bottom-up' polygenetic influences, to 'top-down' supportive social influences. We highlight the complex nature of resilient functioning and suggest how future studies could embrace a complexity theory approach and investigate multiple levels of biological organisation and their temporal dynamics in a longitudinal or prospective manner. This would involve using methods and tools that allow the characterisation of resilient functioning trajectories, attractor states and multidimensional/multilevel assessments of functioning. Such an approach necessitates large, longitudinal studies on the neurobiological mechanisms of resilient functioning after childhood maltreatment that cut across and integrate multiple levels of explanation (i.e. genetics, endocrine and immune systems, brain structure and function, cognition and environmental factors) and their temporal interconnections.
\end{abstract}

Conclusion: We conclude that a turn towards complexity is likely to foster collaboration and integration across fields. It is a promising avenue which may guide future studies aimed to promote resilience in those who have experienced childhood maltreatment.

Keywords: Childhood maltreatment, Abuse, Neglect, Neurobiology, Resilience, Psychopathology, Genetics, Neuroendocrine, Inflammation, Brain structure, Brain function

\section{Background}

Up to a third of children growing up worldwide experience childhood maltreatment $(\mathrm{CM})[1,2]$, which can be defined as "any act, or series of acts by a parent or caregiver that results in the (potential for) harm, or threat of harm, to a child". It comprises of abuse (i.e. sexual, physical and emotional) and/or neglect (i.e. physical and emotional) [3]. Children exposed to even a single episode of $\mathrm{CM}$ are at risk of repeated, more severe and more physical types of abuse or neglect [3-6]. CM is associated with poor functioning across a wide range of

\footnotetext{
* Correspondence: konstantinos.ioannidis@cpft.nhs.uk;

av391@medschl.cam.ac.uk

${ }^{1}$ University of Cambridge, Department of Psychiatry, 18b Trumpington Rd,

Cambridge CB2 8AH, UK

Full list of author information is available at the end of the article
}

domains - it has been associated with problems directed towards the self (i.e. negative self-cognitions [79], alcohol abuse, impulse control problems [10] and suicidal behaviours [11]), interpersonal difficulties (i.e. increased peer rejection [12], social withdrawal [13], aggression and criminality [14]), physical health difficulties (i.e. failure to thrive, higher medical morbidity and mortality, e.g. see [3]), cognitive problems (i.e. impaired learning, working memory, verbal fluency and cognitive flexibility $[15,16])$ and mental health disorders $[13,17,18]$.

Although CM is associated with considerably lowered odds of good mental and physical health functioning later in life, a significant proportion of individuals with a history of CM function 'better than expected', when compared to other individuals exposed to CM. Those

(c) The Author(s). 2020 Open Access This article is distributed under the terms of the Creative Commons Attribution 4.0 International License (http://creativecommons.org/licenses/by/4.0/), which permits unrestricted use, distribution, and 
individuals, who may flourish in a single or multiple domains (e.g. socially, academically) [19], have been described as to be functioning 'resiliently' [20-22]. In this review, we highlight the complexity of neurobiological factors that aid such resilient functioning after CM by discussing the dynamic interplay of factors, which range from 'bottom-up' polygenetic influences to 'top-down' supportive social influences. In doing so, we argue that the neurobiology of resilient functioning after $\mathrm{CM}$ should be described and examined as a 'complex dynamic system'. We suggest that future studies on resilient functioning after CM could move the field forward significantly by embracing a complexity theory approach. This would involve investigating multiple levels of biological organisation and their temporal dynamics in a longitudinal or prospective manner.

\section{Main body}

\section{Resilient functioning after $\mathrm{CM}$}

Resilience denotes the ability of an organism to adapt to changing environments and cope with environmental challenges by shifting within its normal operating range [23]. There is considerable heterogeneity in the exact definitions used to describe resilience after CM (e.g. see [19, 24]). However, an emerging consensus in the field is that resilience refers to a positive outcome, or adaptation, following adversity [22, 25-27]. In individuals with CM, manifestations of this process are commonly inferred or determined in the aftermath of $\mathrm{CM}$ in the form of resilient functioning at a given time point from a given trajectory [22]. Considering the negative impact of $\mathrm{CM}$ on a broad range of domains, such resilient functioning after $\mathrm{CM}$ should be inferred from functioning across social, emotional, cognitive and/or behavioural domains [20].

Individual differences in the degree of resilient functioning should take into account the severity of the adverse experiences, such that resilient functioning refers to better mental wellbeing compared to others with a similar degree of adverse experiences [27]. In other words, a moderate level of functioning can indicate a higher degree of resilient functioning for someone with a severe history of $\mathrm{CM}$ when compared to someone with moderate or low CM. Figure 1 illustrates how multivariate techniques can be used to quantify resilient functioning as psychosocial functioning conditional on the degree of $\mathrm{CM}$ experiences. Here, the level of resilient functioning is inferred from the residuals of the relation between CM severity and psychological functioning across domains - the extent to which an individual is functioning better than expected given their $\mathrm{CM}$ experiences (implying resilient functioning, green lines) or worse than expected (implying vulnerable functioning, red lines) (Fig. 1, for a similar approach see [28-30]). Such a conceptualisation of resilient functioning entails an a priori strong association between psychosocial functioning and the measures of functioning (as the residuals will, by design, be highly correlated with psychosocial outcomes). However, it explicitly separates the two more clearly towards the extremes of CM severity - individual $\mathrm{A}$, who has experienced little or no $\mathrm{CM}$, will have lower resilient functioning scores than individual $\mathrm{B}$, who experienced severe $\mathrm{CM}$, even if the latter may have lower absolute psychosocial functioning (example highlighted in Fig. 1).

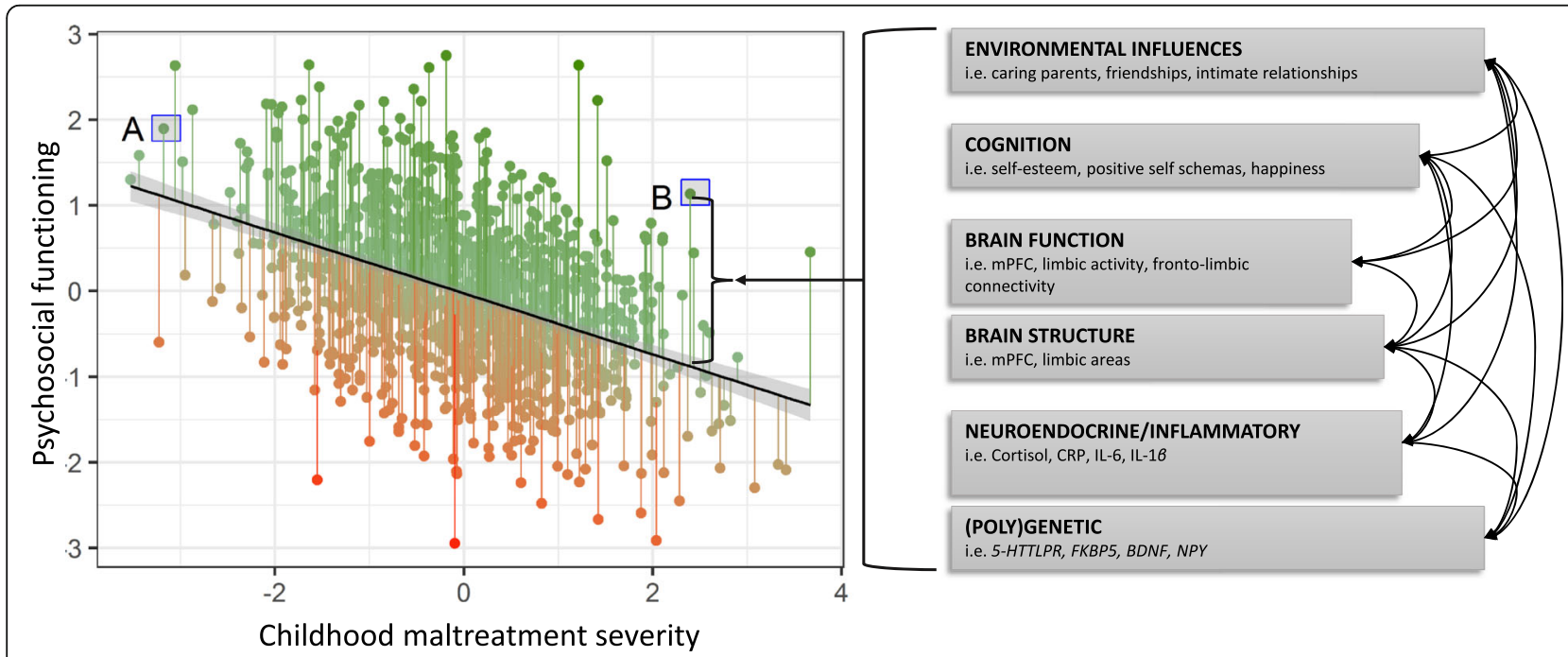

Fig. 1 Resilient functioning and resilience factors. Individual resilient functioning as determined by the residual scores from the relationship between early life stress and psychosocial functioning. The residual scores reflect the extent to which an individual functioned better than expected (green lines, positive score) or worse than expected (red lines, negative score), given their history of childhood maltreatment (CM). Note that both axes represent factor scores with mean $=0$ and $S D=1$. a represents an individual who has experienced moderate $C M$ and has lower resilient functioning scores than someone with lower psychosocial functioning who experienced severe CM (b) 
Resilient functioning after $\mathrm{CM}$ is thought to be facilitated by protective 'resilience factors' that help individuals to adapt and recover from, or compensate for, the sequelae of CM [21, 31]. These resilience factors comprise skills and resources linked to better outcomes in the face of adversity. Therefore, by measuring and/or assessing such resilience factors, an individual's capacity for resilience could be assessed before stressor onset [32] - this is particularly important when considering interventions that could boost capacity for positive adaptations to adversity after $\mathrm{CM}$. In the following paragraphs, we show how these resilience factors reside on multiple explanatory levels, ranging from genes to social influences [33], and describe how these factors are related to each other to facilitate resilient functioning after CM (Fig. 1). We refer readers to excellent narrative and systematic reviews of social, cognitive and behavioural [33], neurobiological [34-38], and psychobiological and molecular genetic factors of human resilience $[23,39]$ as well as animal models of resilience [36, 40].

\section{The complex interrelations of social, cognitive and neurobiological influences that facilitate resilient functioning after $\mathrm{CM}$}

The human brain plays a key role in resilient functioning by orchestrating behavioural and physiological responses to stressors [41] (Fig. 2). The prefrontal cortex (PFC), for example, is critically involved in the executive control of cognitions, emotions and stress responses [42]. Surprisingly rudimentary properties of the PFC seem to be important for those brain functions, wherein larger PFC volumes are associated with improved performance in aspects of executive functioning (e.g. working memory) in healthy adults [43]. Two recent reviews of the neuroimaging literature suggest that resilient functioning in those with a history of CM (i.e. the absence of any mental health disorder as an outcome [44] or the absence of post-traumatic stress disorder [45]) has largely been examined only cross-sectionally and is related to altered volumes and/or function of (midline) PFC as well as to limbic regions and their functional connectivity [45-47]. For instance, in the multisite IMAGEN study ( $n=1870$ adolescents), larger right middle superior PFC volumes were shown to be associated with resilient functioning on multiple domains of functioning, including academic achievement, conduct, relationships and emotional health [48]. These studies provide some evidence that, cross-sectionally, larger PFC volume may be related to resilient functioning after CM. Further support for this idea comes from longitudinal behavioural studies revealing that smaller PFC volume after CM is linked to later poor cognitive functioning [49] and worsened illness courses [50]. However, it is not clear to what extent individual differences in the volume of the PFC are pre- existing vulnerability factors in those at risk or represent adaptive growth responses to stress in resilient individuals. To our knowledge, the only study that specifically examined PFC growth trajectories after CM found delayed maturation in the superior frontal gyrus in early adolescence, and that relative thickening of the superior frontal gyrus mediated the association between poor late adolescent functioning (i.e. decreased global functioning and lower rates of school completion) in boys who had experienced high maternal aggressive behaviour [51]. Thus, although some cross-sectional studies indicate that greater PFC volume is associated with resilient functioning after $\mathrm{CM}$ in adolescents, longitudinal evidence suggests more complex patterns. There is a clear need for further longitudinal research with designs that capture neurodevelopmental growth trajectories to examine the exact role of PFC volume and growth in resilient functioning after $\mathrm{CM}$.

One likely explanation for the associations between PFC structure and resilient functioning is that the PFC plays a key role in the ability to regulate one's emotions [52]. Such emotion regulation capacity is critically important in daily life and has been linked with a better ability to downregulate threat and stress responses as well as with improved mental health outcomes [53]. An increased emotion regulation capacity and associated brain functioning has been linked to resilient functioning after CM [54-56]. Such improved emotion regulation capacity may help resilient individuals to cope better with additional and/or daily life stress $[57,58]$ through their improved ability to downregulate and/or reappraise stress responses. The medial PFC plays an important role in inhibiting stress responsivity in the limbic regions $[59,60]$ and increased inhibitory activity in the rostral anterior cingulate cortex (ACC) has been linked to resilient functioning after $C M$ [61]. This interpretation is supported by findings that healthy males with a history of $\mathrm{CM}$ showed limbic deactivation in response to stress [62] and that CM was negatively associated with amygdala and subgenual ACC responsivity to mild stress in healthy adults [63]. Such reduced activity of the limbic system is key, as limbic activity activates the hypothalamic-pituitary-adrenal (HPA) axis and stimulates the release of glucocorticoid hormones and proinflammatory biomarkers in the periphery [64] in two separate but inextricably intertwined biological systems - the HPA axis and the immune system [64]. In the next section we will describe how these processes have been linked to vulnerable and resilient functioning after $\mathrm{CM}$.

\section{The hypothalamic-pituitary-adrenal axis}

The HPA axis is the core component of the neuroendocrine system that controls stress reactions, immune functioning and other physiological processes. In response to 


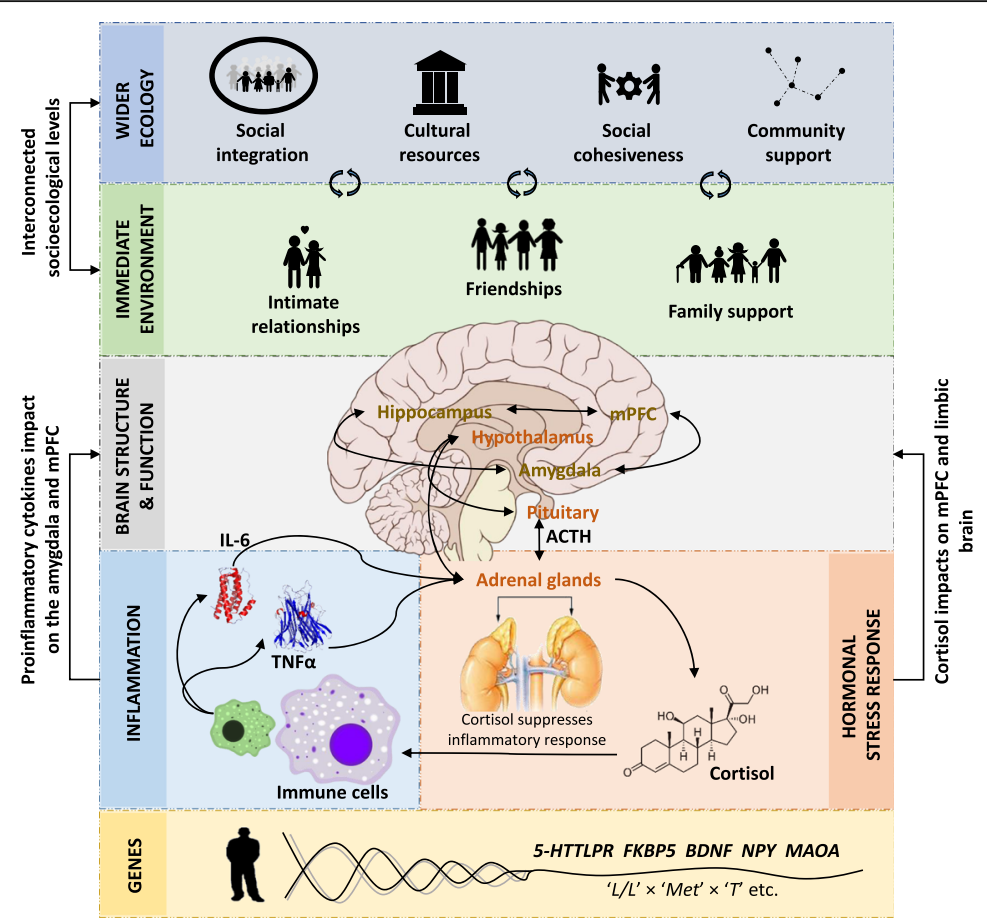

Fig. 2 The complex neurobiology of resilience after childhood maltreatment (CM). Resilient functioning in those individuals who have experienced CM may be facilitated by larger prefrontal cortex (PFC) and hippocampal volume and connectivity, the ability to adequately regulate emotions and dampen stress responsivity, cortisol and proinflammatory baseline and responses, polygenic resilience effects, social support from the immediate environment, and the wider ecology. For readability, the location of the hippocampus is not correct. 5-HTTLPR serotonintransporter-linked polymorphic region, ACTH adrenocorticotropic hormone; BDNF brain-derived neurotrophic factor, FKBP5 FK binding protein 5 , IL-6 interleukin 6, MAOA monoamine oxidase A, MPFC medial PFC, NPY neuropeptide-Y, TNFa, tumour necrosis factor-a

stress, the hypothalamus releases corticotropin-releasing hormone, which activates the release of adrenocorticotropic hormone from the anterior pituitary, which, in turn, stimulates the release of the stress hormone cortisol from the adrenal cortex. Cortisol is a glucocorticoid hormone that, among a wide array of functions, suppresses peripheral cellular and molecular inflammatory responses and binds with glucocorticoid receptors in the PFC and limbic structures to control brain development and responses [65].

In the context of $\mathrm{CM}$, recurrent stress would lead to a chronically activated HPA system, which may lead to adrenal 'fatigue' and, via downregulation, to chronic adrenal stress hyporeactivity [66-69]. CM has diverse and profound effects on the endocrine system, as demonstrated in populations with a variety of adverse experiences, including single trauma [70], neglect [71] and social deprivation [72]. Results of these studies, summarised in recent meta-analyses and reviews, are mixed, with CM being related to both blunted and higher baseline cortisol, cortisol response to awakening and acute stress responses [73-76]. It has been suggested that the associations of cortisol with CM differ for patients with and without psychopathology [73]. Indeed, a recent meta-analysis that focused on healthy non-clinical populations reported that $\mathrm{CM}$ was associated with an increased cortisol awakening response and lower baseline cortisol levels [76]. However, to our knowledge, a direct comparison between clinical and healthy populations on baseline, awakening and stress responses for cortisol in individuals with $\mathrm{CM}$ has not yet been conducted.

The above evidence suggests that cortisol levels and responses may be related to resilient functioning after CM, although the specific direction of this relationship is unknown. In addition, glucocorticoids interact with other adrenal hormones such as the steroid androgen dehydroepiandrosterone (DHEA). DHEA acts as a natural antagonist to cortisol [77], may protect against the harmful effects of hypercortisolism [37, 78] and aids resilient functioning towards outcomes of depression [79, 80]. However, other findings suggest a more complex picture; for example, resilient functioning in a large sample $(n=677)$ of school-age maltreated children was positively associated with high morning cortisol, lower morning and afternoon DHEA, and higher morning and afternoon cortisol to DHEA ratios [78]. These findings emphasise the complex interplay of neuroendocrine factors that may facilitate resilient functioning after CM as well as the need for studies with large samples to yield precise and reliable estimates. A key pattern seems to be that maladaptive changes in the 
stress system after CM are associated with dysfunctional neurodevelopment, suggesting the presence of feedback loops operating on the interface of neuroendocrine and neural systems. For example, testosterone, when injected, can directly influence dominant or aggressive behaviour and is found to correlate positively with such behaviours [81], illustrating that the causal relationship may also be reversed - certain behaviours may themselves lead to an increase in testosterone, which in turn affects behaviour. Likewise, CM mediated the relationship between fractional anisotropy in corticomotor projections and baseline sympathetic nervous system activation, though not during cortisol administration challenge; these results may potentially suggest an altered neural circuitry having modulating effects in a network of neuroendocrine parameters of stress [82]. Furthermore, stress-sensitive hippocampal areas have been shown to be significantly smaller in children with $\mathrm{CM}$, and $\mathrm{CM}$ moderated the positive linear relationship between left hippocampal volume and diurnal cortisol [83]. In sum, the processes that facilitate resilient functioning after $\mathrm{CM}$ may be reciprocal in nature, with simultaneous influences from neurophysiological properties to behaviour and vice versa.

Thus, while the neurodegenerative potential of glucocorticoids has robustly been demonstrated in preclinical studies $[84,85]$, the underlying mechanisms have not directly translated to human studies of CM. This suggests a more complex picture and a need to consider multiple biological levels (genetics, personality, behaviour, clinical phenotypes) to make sense of the interplay between neuroendocrine and neural factors [86]. One possible explanation for the difficulty in disentangling the causal effects between such processes is that they are not unidirectional, linear or additive, but rather highly dynamic and bidirectional, likely involving non-linear feedback loops between (sub)components of the systems [87]. This highlights the importance of future studies combining large samples with high temporal resolution of measurements as well as quantitative, complex systems approaches that are able to disentangle this web of reciprocal effects. Below, we highlight several cuttingedge tools that may offer researchers at least some traction on this highly complex and multifaceted problem.

\section{The immune system}

In response to stress, the sympathetic nervous system activates immune cells to propagate an inflammatory response. Specifically, via central and peripheral nervous system monoamine actions, the sympathetic nervous system propagates the release of proinflammatory biomarkers such as interleukin 6 and tumour necrosis factor- $\alpha$ (Fig. 2) [88]. Proinflammatory biomarkers play a key role in both stress reactivity and recovery [89-93]. Specifically, proinflammatory cytokines stimulate the
HPA axis to release glucocorticoid hormones, such as cortisol, which in turn suppress the further release of cytokines from the immune system [94]. Over time, however, chronically elevated inflammatory responses lead to glucocorticoid resistance, with cortisol losing its antiinflammatory efficiency [95]. Through this pathway, chronic stress in the context of CM may facilitate sustained inflammation in the periphery. Indeed, CM experiences have been linked to increased levels of peripheral inflammation biomarkers [96-99]. Changes in proinflammatory cytokines and glucocorticoid systems have also been associated with structural changes in brain regions crucial for emotion regulation and stress response [93, 100] (Fig. 2). Elevated proinflammatory biomarkers can cross the blood-brain barrier in various manners and negatively impact on the structure and function of brain regions involved in threat, reward and executive processing [89, 101]. Thus, the neural, immune and endocrine systems are closely linked in regulatory feedback loops that control stress responses and adaptation after CM.

Through their impact on the brain, proinflammatory biomarkers are thought to play a role in initiating and perpetuating mental health disorders [90, 102-109]. While low inflammation appears protective towards the development of mental disorders, there is currently no empirical evidence to support the notion that low levels of proinflammatory biomarkers facilitate resilient functioning after $\mathrm{CM}$ in humans. Some insights have been obtained by mechanistically robust animal studies, wherein stress-resilient mice had lower plasma corticosterone levels, lower PFC mRNA expression of corticotrophin-releasing factor and lower inflammatory circulating monocytes compared to stress-susceptible mice [110]; those mice also differed with respect to their hippocampal synaptic plasticity.

From the above, it is clear that HPA axis and immune interactions with the brain are involved in resilient functioning after CM. Future studies are needed to elucidate the exact role of the immune system in its interaction with HPA axis components as well as in relation to brain structure and function in resilient functioning after CM. Such studies may reveal empirical evidence supporting the role of immunological processing in resilient functioning after CM. Nevertheless, it seems likely that the mechanisms that connect neural, immune and endocrine systems to resilient functioning are closely linked, inherently dynamic and non-linear.

\section{The role of polygenetics}

Evidence from behavioural genetics suggests that individual differences in resilient mental health functioning has a significant heritable component, estimated at 50\% [30]. Genes shape the neuroendocrine and immunological consequences 
of $\mathrm{CM}$ and therefore contribute to brain structure and functioning after $\mathrm{CM}$. Indeed, a number of neuroimaging studies have identified gene $\times$ environment interactions $[111,112]$. For example, brain-derived neurotrophic factor (BDNF Val66Met polymorphism) [113-116], serotonin-transporterlinked polymorphic region (5-HTTPLR) in SLC6A4 [50, 117], neuropeptide-Y (NPY) gene polymorphism rs16147 [118], monoamine oxidase A (MAOA) gene [119-121] or the FK506 binding protein 5 (FKBP5) gene [122] interact with $\mathrm{CM}$ to predict mental health outcomes. However, these findings must be viewed as preliminary because the field suffers from publication bias towards positive results $[115,123]$. Indeed, a recent meta-analysis of 31 datasets containing 38, 802 subjects found no support for a CM $\times 5$-HTTLPR interaction, although $\mathrm{CM}$ was found to have a main effect on risk for depression [124]. Moreover, in a recent overview of large population case-control studies of depression, no evidence was found for any polymorphism-by-environmental moderator effects, including CM [125].

Genetic effects are often polygenic [126, 127]. Thus, the presence or absence of certain haplotypes may interact with other genes ('polygenic resilience factors') to facilitate resilient functioning after $\mathrm{CM}$. For example, the $B D N F$ met allele was protective against the influence of the 5-HTTPLR $S$ allele risk on subgenual ACC and its structural connectivity with the amygdala [128]. However, establishing associations suggestive of 'polygenic resilience factors' is a daunting task children bearing the haplotypes associated with positive outcomes later in life may also be growing up in more supportive home environments (and inherited both their haplotypes and a supportive home environment), whereas children with risk genes may be growing up in more adverse or 'depressogenic' environments [129].

Overall, there are significant challenges ahead for future research on the genetic determinants of resilient functioning after CM. Studies should use genetically sensitive designs because of potential intergenerational transmission of genes and environments that promote resilient functioning. They should also consider the complexity of polygenic influences in which a variety of haplotypes might interact with each other to promote resilient outcomes. Moreover, to ensure a more holistic, integrative understanding, such studies should ideally assess how polygenic and environmental influences interact with multiple levels of biological organisation simultaneously, rather than linking genetic markers directly with distal outcomes of psychopathology. Finally, to ensure the robustness and replicability of findings of effects that are likely to be small in size, large samples as well as other innovations, such as registered reports, are crucial [130].

\section{The social environment}

Positive environmental influences at all levels of the social environment (i.e. family, culture, social capital, social connectedness, community and their transactions) play a key role in promoting individual resilient functioning after CM [26, 131-134]. There is over 50 years of research showing the importance of social environmental influences on resilient functioning after CM [135]; whilst an appropriate inclusion of this literature would be warranted, this is outside the scope of the current review. As such, we refer readers to key papers on the importance of the social environment [26, 33, 131-138] and provide some examples below. Family support in adolescence as well as peer support is associated with reduced depressive symptoms and promotes resilient functioning across a range of domains in those who have experienced CM [12, 139]. The beneficial effects of social support may be mediated through neurobiological mechanisms that facilitate resilient functioning after $\mathrm{CM}$; for example, experimental animal studies showing adverse effects of early life stress on neurobiology can be reduced through positive environmental changes during the animal equivalent of adolescence [140-143]. Specifically, environmental enrichment offered to juvenile rats who had been exposed to in utero stress increases their play behaviour, reduces emotionality, enhances antiinflammatory cytokines [140] and reduces corticosterone response to immediate stress [142]. Similar findings have been reported in humans, where friendship interactions and higher social status were associated with a reduction in behavioural distress and distress-related medial PFC function alterations after exposure to simulated peer rejection in a lab setting [144-147]; in turn, this was associated with reduced peripheral inflammation (interleukin 6) levels [146]. Furthermore, earlier age of adoption or foster care from institutions has been associated with more typical amygdala discrimination between maternal and unfamiliar facial expressions [148] and more normative white matter development [149]. These studies provide preliminary empirical evidence that particular positive environmental factors (e.g. environmental enrichment, (new) familial support, social support, friendships) may support more resilient functioning through acting on core neurobiological processes (cytokines, HPA axis, brain structure and function), even after the maladaptive early environmental experiences occurred.

In addition to these immediate associations between social support and resilient functioning on an individual level, it is important to acknowledge the key role that immediate and wider social structures, such as communities, culture and societal integration, play in facilitating individual resilient functioning after CM. A socioecological system (e.g. a community of people with a shared cultural background) that is able to maintain the integrity of its supportive resources, infrastructure and social networks in the face of adversity (e.g. racism, colonisation, marginalisation, dispossession, societal disintegration, loss of language 
or culture) may form a crucial context for resilient functioning at the level of the individual [150-154]. For example, Panter-Brick et al. [155] showed that young Syrian refugees are able to function resiliently through drawing strength from positive relationships in their community. This is in line with previous findings and hypotheses that factors operating in the society of resettlement are critical for mental health outcomes among refugees [156]. For instance, cultural continuity in health services influenced positive mental health outcomes in the Aboriginal populations of Canada [154]. Furthermore, research in highstress populations where little support is available (e.g. child soldiers and maltreated or racially marginalised children) has shown that individual-level characteristics account for less variability in outcomes compared to environmental characteristics (e.g. [157]; see [137]). Thus, the characteristics of the wider socioecological system are essential to understanding resilient functioning at the individual level.

While individual systems operate in constant interaction with multiple layers of ecology, resilience may stem from these complex interactions throughout development. This notion is sometimes referred to as 'systemic resilience' [138] and has been utilised to explore resilience with a focus on the family system (systemic resilience in families) [158] and/or the wider ecology (systemic resilience in multiple ecological layers) [138] as well as the interaction between systemic resilience and resilient functioning at an individual level in those who have experienced CM. Multisystemic resilience expands from the viewpoint of Developmental Systems Theory [159], in which a person's development is affected by the complex interactions of several systems external to the individual, embedded in multiple ecological layers. Thus, responses to adversity in any one individual may be crucially affected by the family system, depending on the wider community and the prevailing values of their culture and society [150]. From the perspective of Developmental Systems Theory, contextual variables such as culture should be considered as an important moderator in studies on resilience. In fact, according to this perspective, the individual may not always be the most important locus of change in complex systems [137]. Therefore, future resilience research would benefit from consideration of the complex developmental interactions between multiple ecological systems to allow for the detection of important contextual mediators and moderators of systemic resilience.

\section{Towards a complex systems approach to resilience}

Resilient functioning after $\mathrm{CM}$ relies on interactions that cut across multiple levels, ranging from the genetic to the societal level, that interact through regulatory loops to create a complex network of interactions (Fig. 2). As such, a more comprehensive understanding of resilient functioning after CM necessitates an appropriate conceptual framework to do so. We propose that complexity theory is one such framework, with its emphasis on complex systems as highly composite systems, built up from multiple interacting subunits [160], with bottomup as well as top-down regulatory loops. If we consider resilient functioning as the higher-level manifestation of a complex developing system composed of subunits and regulatory loops, resilience factors can affect subunits or the nature of the interactions and regulatory networks. As such, resilience factors can be described as network nodes influencing interconnected and auto-connected 'networks' of symptoms (hybrid symptom-and-resilience networks) that dynamically guide clusters of symptoms through stress adaptation over time [161]. However, to truly help the field of resilience research move forward, complexity theory must offer analytical tools as well as a tractable conceptual framework to guide and inform research. Below, we briefly outline several promising quantitative approaches, innovations that are increasingly being applied in mental health research and are likely to confer considerable benefits on future studies of resilience.

\section{The longitudinal dynamics of resilience}

As outlined above, we conceptualise the neurobiology of individual resilience as an inherently dynamic process. This view is in accordance with Developmental Systems Theory, which proposes that resilience arises from complex dynamic interactions involving many processes within and between systems [32, 162]. Such systems comprise many kinds of interacting levels, ranging from microorganisms (e.g. the microbiome) to families, the economy and the global climate [32, 138, 162]. From the perspective of complexity theory, the temporal dynamics of complex systems can be described as deterministic, semideterministic and indeterministic, based on whether it is possible to predict past and future trajectories from their initial state [160]. By definition, the values taken by a complex system's variables at any point in time $\left(T_{x}\right)$ describe the system's state $\left(S_{x}\right)$, which can be represented by a point in a geometrical space [160]. The dimensions of such a system and space depend on the range of processes and variables included. Adding time, 'space' becomes 'phase space' - each point in the phase space represents a state in which the system could be at one time, corresponding to an assignment of particular values to the variables at a given instant [160]. The path that the systems follow through phase space can be described as the 'trajectory of the system'.

Using such trajectories in phase space, we can quantify resilience over time by studying how system states evolve from the beginning to the end of the observational period. 
Using the method described in Fig. 1, resilience can thus be quantified through phase space as the integration of the system's trajectory against the regression surface. To illustrate this, we have plotted a hypothetical trajectory of a complex system (say an individual) with their scores of psychosocial functioning ( $y$-axis) and CM severity ( $\mathrm{x}$-axis) through time (z-axis), within a cohort of individuals (only presented as data points in $\mathrm{T}_{1}$ ) (Fig. 3). We have also plotted a regression surface ('resilience hyperplane'); all data points above the hyperplane (green) characterise 'resilient functioning', whereas all data points below the hyperplane (red) characterise non-resilient functioning at any point in time (cross-sectionally).

Using Fig. 3 we can demonstrate why better understanding of resilience necessitates longitudinal data and techniques - if we consider an individual's (complex system) trajectory through phase space, measuring this individual's resilient functioning at $\mathrm{T}_{1}, \mathrm{~T}_{2}$ or $\mathrm{T}_{3}$ would result in variable resilient functioning scores (positive at $\mathrm{T}_{1}$, negative at $\mathrm{T}_{2}$, positive again at $\mathrm{T}_{3}$ ). As such, if measured crosssectionally, the individual would be characterised as 'resilient' at $T_{1}$ and $T_{3}$, and 'vulnerable' at $T_{2}$. Although these states may accurately reflect the functioning of an individual at that moment, it is the variability and trajectory that yield a true understanding of the dynamics of the system as well as better quantification of resilient factors that support 'upwards' trends. In Fig. 3, the shaded grey area represents a hypothetical period of adverse experience(s). By studying such a trajectory longitudinally, additional adverse experiences, whereby an external stressor affects an individual's psychosocial functioning, would further enable the untangling of the role of mental health predispositions and would thus allow for a more detailed investigation of residuals as markers of resilient functioning. This would then allow for the investigation of resilience mechanisms, the underlying processes by which resilience factors may facilitate resilient functioning in the aftermath of CM.

Such resilience mechanisms may manifest at different levels of abstraction, for instance, as moderating or mediating effects $[163,164]$. Moderators directly affect the strength of the relationship between some form of adversity and an outcome, providing either a buffering or an amplifying effect. For instance, we observed that individuals who experienced more negative life events showed a stronger association between their positive memory specificity and negative self-cognitions [165]. In other words, individuals who had access to more specific positive memories displayed resilience against negative self-cognitions after negative life events. Mediators may provide specific, temporally ordered mechanisms through which (e.g. negative) events have distal effects. In the same paper, we found that individuals with greater positive memory specificity experienced fewer negative self-cognitions, which in turn led to fewer depressive symptoms [165]. In other work, we demonstrated that children who experienced greater childhood adversity showed greater depressive symptoms 3 years later, in part due to the mediating mechanism whereby greater CM negatively affected both friendships and family support in the intervening years

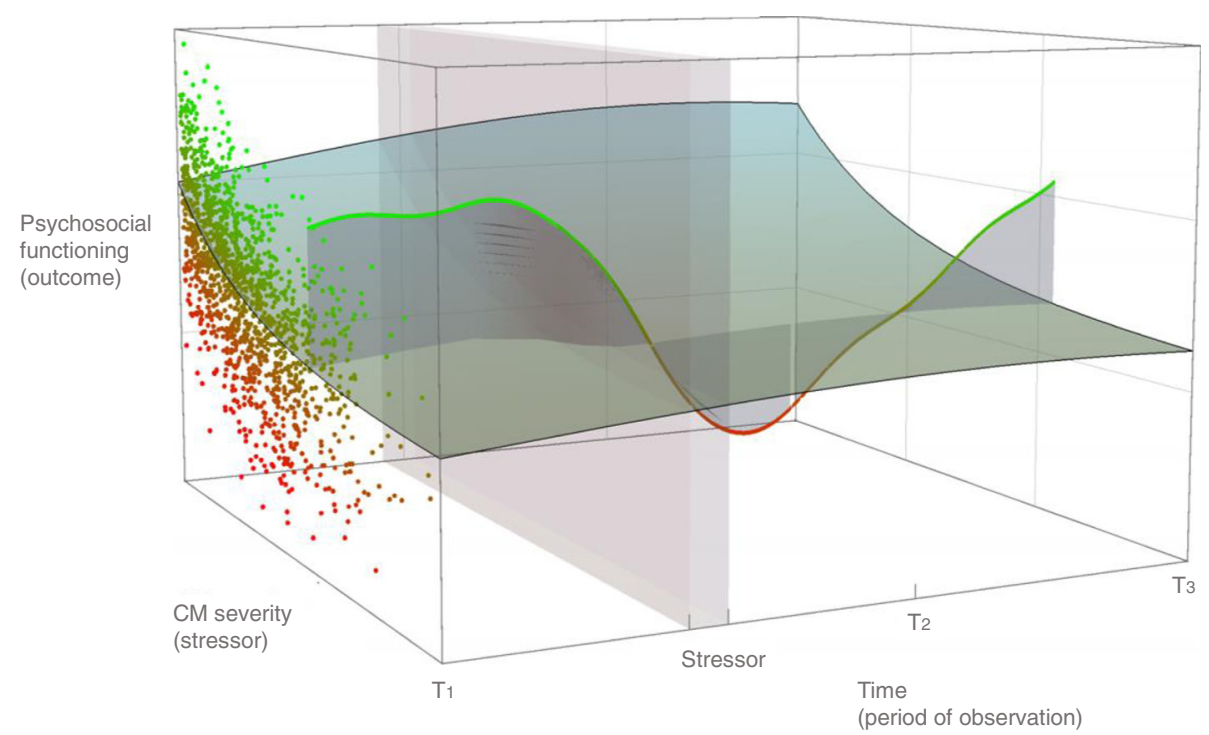

Fig. 3 Trajectory of a complex resilience system in phase space. Resilience hyperplane plot of simulated data of childhood maltreatment (CM) severity ( $x$-axis: stressor variable), psychosocial functioning ( $y$-axis: outcome variable) and time (z-axis: period of observation), created by fitting a polynomial regression surface determined by numerical predictors of $x, y$ and $z$ using local fitting. An individual trajectory was hypothesised to demonstrate a complex system trajectory above and below the regression plane. Data points above the hyperplane (green) characterise 'resilient functioning', whereas all data points below the hyperplane (red) characterise non-resilient functioning at any time point (cross-sectionally) 
[12]. Both findings of moderating and mediating mechanisms can allow researchers to quantify the capacity of an individual for resilient functioning, even in the absence of any negative events having occurred. This could ultimately be used to understand and guide interventions that could boost the capacity of (groups of) individuals to display resilient functioning when exposed to adversity.

In sum, quantification of an individual's trajectory through phase space and the degree to which it can be predicted (determined) based on a number of known parameters (values) for their initial conditions will confer various scientific and translational benefits, including early warning markers, identification of resilience factors and quantification of temporal changes during development. Next, we will examine how to better understand the nature of these trajectories.

\section{Understanding attractor states}

A key concept from complexity theory relevant to resilience is the notion of an 'attractor' in complex systems; the attractor is a region in $\mathrm{n}$-dimensional space towards which an agent in an environment has a tendency to move or return. Complex systems may display a particular behaviour of how they move through phase space after an intervention or stress in the system, they may have a transient period during which they move in a specific direction through phase space, before returning back to their 'normal' behaviour. The phase space points corresponding to this 'normal' behaviour form the system's 'attractor'. Previous work provides many empirical examples of such attractor states. For example, following the loss of a spouse or child, individuals often retain or return to their pre-loss mental health levels [166]. This concept is crucial to understanding resilience. Resilience can be theorised as an attractor; after interventions or stressors, the resilient system has the tendency to return to a particular area of the phase space in which its functionality has returned back to 'normal'. In the 'resilience hyperplane' paradigm (Fig. 3), the presence of a 'resilience attractor' would suggest the tendency of a system to return towards the higher values of the y-axis (psychosocial functioning), within a range of cumulative stress ( $\mathrm{x}$-axis), as time passes following a stressor. In other words, the presence of a resilience attractor would indicate that a system would tend to return to the area of phase space that has a specific range of values characterising normal functioning. In turn, resilience factors are those influences that may have the capacity to push an individual's attractor state to a more well-adjusted region of this high-dimensional phase space. It is important to note that resilience, as an attractor state, does not imply that the resilient system is rigidly seeking to return to its exact adaptive functioning of the past or that the adaptations are 'specific' or 'permanent'. Rather, attractor states describe areas of phase space in which return to normal function may be achieved through transformative change or reorganisation and in which the capacity to flexibly find new solutions to new problems is embedded in the resilient system.

\section{Statistical techniques to investigate complexity in resilience research}

The inherent complexity and dynamic nature of resilience after $\mathrm{CM}$ has been outlined in some detail above. However, to allow true scientific progress, we must harness techniques that can translate, capture and render tractable this complexity. Only by doing so can we translate the scientific study of complexity into quantitative models and make progress towards the ultimate goal of facilitating early detection, prevention and treatment. To achieve this goal, there has been an emerging appreciation for statistical techniques that can capture the phenomena of interest in ways that do justice to their inherent complexity. For instance, new work has shown how a range of quantitative techniques can capture nonlinear dynamics (e.g. [167, 168]), early warning signals (e.g. [169]), bifurcations and attractor states (e.g. [170]), processes that are often discussed (usually in a qualitative sense) to describe developmental trajectories across explanatory levels. Beyond the academic literature, more accessible online resources, put together by worldrenowned experts in complexity theory [171], provide a valuable starting point for researchers interested in translating ideas from complex systems into quantitative approaches. Below, we highlight a small number of quantitative approaches readily available and refer readers to specialised literature for in-depth discussions of these techniques.

Techniques such as Structural Equation Modelling (SEM) [172] can be profitably used to integrate notions of mediation, moderation and integration across multiple levels and timepoints. SEM is an overarching method that incorporates path analysis as well as latent variables, which may have advantages when studying resilience in large datasets with many variables. Path modelling is a more flexible extension of regression analysis [172] and is well suited to study complex resilience factors and processes as it can integrate data and hypothesised relations from multiple explanatory levels. For instance, using path modelling, we recently found that recalling specific positive memories was associated with reduced cognitive and physiological vulnerability to depression over two time points in adolescents exposed to childhood adversity [165]. Path analysis can also be used to test hypotheses of mediation and moderation, which may be of particular relevance in resilience studies investigating whether resilience factors and mechanisms moderate and/or mediate 
the relation between $\mathrm{CM}$ and mental wellbeing. Combining mediation and moderation using, for instance, conditional process analysis [164] can simultaneously address questions about the mechanisms behind resilience (mediation) and the conditions governing the strength of the linking mechanisms (moderation). In addition, SEM can be useful for integrating, or reducing, high-dimensional data. Beyond simple data reduction, latent techniques enable multidimensional conceptualisations of resilient functioning (i.e. across symptoms, cognitions and personality traits; see [139]). SEM is more flexible than regressionbased techniques and offers robust handling of missing values, which is important in longitudinal studies [172]. SEM can be used to examine comprehensive integrative resilience models, for example, Kievit et al. utilised SEM to examine a 'watershed' model of the complex interrelations of brain structure, cognitive function and general intelligence [173].

Most importantly for resilience studies is arguably the quantification of change over time. Latent growth curve modelling [174] is a particularly versatile technique that allows researchers to quantify trajectories of resilient functioning, recovery or illness in longitudinal data. This technique allows for the elucidation and examination of resilient functioning trajectories over time [175] by reducing the impact of measurement error. Moreover, it allows for relatively simple inclusion of predictors of trajectories, the modelling of latent or manifest subgroups with distinct trajectories, and the demonstration of individual differences in trajectories.

Another important, and rapidly emerging quantitative framework is that of network analysis, a method that specifically examines the interrelations among variables. Network analysis has been used profitably in fields of psychopathology to conceptualise disorders as complex emerging phenomena [176]. More recent innovations in psychometric network theory [177] can bridge the gap between confirmatory models (where specific causal hypotheses are tested) and models that allow, in principle, for the full complexity of all interactions. In addition to modelling the direct interactions of symptoms (to help explain phenomena such as depression), network approaches can be utilised to examine complex network systems. For example, we recently utilised network analysis to examine the complex interrelations of resilience factors and their relations with mental health symptoms in adolescents reporting childhood adversity [178], addressing the complexity of resilience. Resilient functioning results from complex interactions between multiple bodily systems [179] and network analyses make it possible to examine interactions between different symptoms and neurobiology at an unprecedented level of detail [180]. In sum, recent statistical innovations have the potential to approach questions of resilience using frameworks that fully embrace the complexity inherent in resilience research.

\section{Discussion}

We argue here that resilient functioning after $\mathrm{CM}$ is facilitated by complex interactions between neurobiological, genetic and social factors. Embracing a complexity perspective and associated statistical methods may aid future research on the neurobiology of resilient functioning after CM. Below, we will highlight three further aspects that such studies should consider.

First, resilience is inherently dynamic [27], such that the trajectories and predictors of resilient functioning may change over time $[6,27]$. This is in line with the emerging literature on resilience from the perspective of Developmental Systems Theory that focuses on complex (dynamic and multilevel) person-oriented models and discusses maladaptive pathways of development and turning points in people's lives [138, 159, 162, 181, 182]. The implications of this are noteworthy - individuals who we describe as to be functioning 'resiliently' at one point in time may not be characterised as such at another, and the environmental and neurobiological factors that predict such resilient functioning may be dependent on the timing of assessment. For instance, in childhood, amygdala hypervigilance may be an adaptive response to a highly stressful environment (for example, in the context of CM, rapid detection of whether a parent is in a bad mood may help the child to avoid a negative confrontation with that parent, leading to 'resilient functioning' in the short term). However, when the individual grows out of that particular social milieu, amygdala hyper-reactivity may form a vulnerability to mental health difficulties [183-185]. From this, it should be clear that the neurobiological elements of resilient functioning after $\mathrm{CM}$ cannot be understood unless they are studied in conjunction with their temporal (and social) dynamics [27, 186-188], quantified by appropriate analytic strategies.

Second, adaptive neurobiological responses after $\mathrm{CM}$ may depend on the type and timing of CM during development. This is in line with the Developmental Systems Theory principles of decentrality and complexity (focus on multiple systems, adaptations and solutions require complex interactions between systems) [138]. Single traumatic experiences and repeated trauma can be quite distinct with regard to the neurobiological sequelae, healing and recovery [189]; the importance of understanding and differentiating repetitive trauma from other types of trauma is also reflected in the recent inclusion of 'Complex Post-Traumatic Stress Disorder' as a separate diagnostic entity in the ICD-11 [190, 191]. Nevertheless, it is also important to appreciate the possibility that such disorders may not be possible to define aetiologically at a 
single level, but rather require considering the causal processes that interact across levels [192]. Threatening (sexual, physical abuse) versus depriving (neglect) experiences may impact on differential brain mechanisms [193]. Moreover, different brain regions have different windows of vulnerability during development (i.e. the life cycle model of stress [194]). Indeed, there is some evidence that the type and/or timing of $\mathrm{CM}$ were a stronger predictor of depression [195], cortisol [76, 78] and inflammation biomarkers [196] than the accumulation of CM occurrences. In support of this idea, the time of CM influences the type of clinical presentation in adolescence [197] and its neurobiological impact [185]. In sum, there may be distinctive neurobiological processes that promote resilient functioning depending on the type and timing of $\mathrm{CM}$ experiences as well as the timing of the resilient functioning assessment; these processes should be the subject of future research.

Third, the severity of $\mathrm{CM}$ matters not only for the quantification of differences in resilient functioning but also for the neurobiological mechanisms at play. Adversity exposure itself may also facilitate resilient functioning. For example, milder and more manageable levels of stress might have a 'steeling' effect on the individual [198], thus promoting resilient outcomes to future stress, a phenomenon described as stress inoculation [199]. Such steeling against depression was mechanistically demonstrated in mice using predictable mild chronic stress [200]. In contrast, high levels of stress have been associated with stress amplification/sensitisation or calibration effects [58, 201-203] (for extensive overviews see $[204,205])$. This evidence demonstrates that a detailed understanding of resilient functioning after $\mathrm{CM}$ is contingent on a proper understanding of the nature and severity of CM experiences.

Finally, although a thorough discussion is beyond the scope of this manuscript, there are many intraindividual cognitive characteristics as well as interindividual family, school, social, and cultural influences that play a critical role in resilient functioning after CM [135-137, 158]. For instance, low ruminative tendencies, high autonomy, high self-esteem and self-efficacy affect resilient functioning after CM [33, 206, 207]. A recent systematic review of the literature suggests key roles for emotion regulation, cognitive skills, empathy and positive outlooks in resilient outcomes in children [136]. Indeed, positive views regarding the cognitive triad of self, the world and the future as well as the ability to remember specific positive events have been associated with a higher level of resilient functioning after CM $[165,208-210]$. Moreover, self-reliance, self-confidence and interpersonal reserve promote resilient adaptations in children with a history of CM [211]. On an interindividual level, positive relationships with caregivers, friends, teachers or other adults, a safe and orderly school environment, student academic achievement, community cohesion and links with cultural identity, including spiritual beliefs, are related with resilient outcomes in children [136]. These findings are crucial, as they suggest, at least in principle, promising intervention targets to facilitate resilient functioning. Thus, neurobiological, genetic, $\operatorname{cog}$ nitive and social factors play a key role in facilitating resilient functioning after $\mathrm{CM}$ and should be considered in future research.

\section{Conclusions}

Resilient functioning after CM is governed by complex interactions between multiple biological and social levels. To further enhance our understanding of resilient functioning after $\mathrm{CM}$, the field may benefit from embracing a complexity theory perspective involving the use of designs that allow the characterisation of resilient functioning trajectories, attractor states and multidimensional, multilevel assessment of functioning. This would include breaking free from reductionist conceptualisations suggesting that biological factor ' $\mathrm{X}$ ' always 'underpins resilience' and acknowledging that resilience refers to the behaviour of a complex system that is high-dimensional and consists of dynamic interactions between multiple explanatory levels. Therefore, resilience should be studied using tools capable of capturing this inherent complexity. Such an approach involves the need for large, longitudinal studies on the neurobiological mechanisms of resilient functioning after $\mathrm{CM}$ that cut across and integrate multiple levels of explanation (i.e. genetics, endocrine and immune systems, brain structure and function, cognition and environmental factors) and their temporal interconnections. A turn towards complexity is likely to foster collaboration and integration across fields. It is a promising avenue towards guiding future studies aiming to promote resilient functioning in those who have experienced CM.

\section{Supplementary information}

Supplementary information accompanies this paper at https://doi.org/10. 1186/s12916-020-1490-7.

Additional file 1: Figure S1. Trajectory of a complex resilience system in phase space (mp4 version). See legend for Fig. 3 for detailed explanation

\section{Acknowledgements}

We thank Susanne Schweizer, Andrea Danese, lan Goodyer and Nicole Creasy for their very helpful comments on earlier versions of this manuscript, Petronella Kievit-Tyson for her scientific editing of the manuscript and Michalis Agathos for his help with plotting Fig. 3.

\section{Authors' contributions}

$\mathrm{KI}$ and $\mathrm{AvH}$ conceptually designed and wrote the first drafts of the review; $\mathrm{Kl}$ and $\mathrm{AvH}$ prepared Figs. 1 \& 2 and $\mathrm{KI}$ prepared Fig. 3. Kl, ADA, RAK and AvH contributed to and revised the manuscript. All authors read and approved the final manuscript. 


\section{Funding}

This work was funded by a Royal Society Dorothy Hodgkin fellowship (ALvH; No DH150176). It was also supported by Health Education East of England (Kl; HEEOE Higher training Special interest sessions), the Aker Scholarship (ADA), the Wellcome Trust (grant number 107392/Z/15/Z; RAK) and the MRC (SUAG/047G101400, RAK). The funders had no role in the design of the study, in the collection, analysis and interpretation of data, or in writing the manuscript.

\section{Availability of data and materials}

Not applicable.

\section{Ethics approval and consent to participate}

Not applicable.

\section{Consent for publication}

Not applicable.

\section{Competing interests}

The authors declare that they have no competing interests.

\section{Author details}

${ }^{1}$ University of Cambridge, Department of Psychiatry, 18b Trumpington Rd, Cambridge CB2 8AH, UK. ${ }^{2}$ Cambridgeshire and Peterborough NHS Foundation Trust/S3 Eating Disorder Service, Addenbrookes Hospital, Hills Rd Cambridge, CB2 0QQ, PO Box 175, Cambridge, UK. ${ }^{3} \mathrm{MRC}$ Cognition And Brain Sciences Unit, 15 Chaucer Road, University of Cambridge, Cambridge, UK.

\section{Received: 22 June 2019 Accepted: 7 January 2020}

\section{Published online: 13 February 2020}

\section{References}

1. World Health Organization. Child maltreatment (Fact sheet no. 150) Geneva: WHO; 2010

2. Stoltenborgh M, Bakermans-Kranenburg MJ, Alink LRA, van IJzendoorn MH. The prevalence of child maltreatment across the globe: review of a series of meta-analyses. Child Abus Rev. 2015;24:37-50.

3. Gilbert R, Widom CS, Browne K, Fergusson D, Webb E, Janson S. Burden and consequences of child maltreatment in high-income countries. Lancet. 2009;373:68-81.

4. Dong M, Anda RF, Felitti VJ, Dube SR, Williamson DF, Thompson TJ, et al. The interrelatedness of multiple forms of childhood abuse, neglect, and household dysfunction. Child Abus Negl. 2004;28:771-84.

5. Edwards VJ, Holden GW, Felitti VJ, Anda RF. Relationship between multiple forms of childhood maltreatment and adult mental health in community respondents: results from the adverse childhood experiences study. Am J Psychiatry. 2003:160:1453-60.

6. Finkelhor D, Ormrod RK, Turner HA. Poly-victimization: a neglected component in child victimization. Child Abuse Negl. 2007:31:7-26.

7. Gibb BE, Alloy LB, Abramson LY, Rose DT, Whitehouse WG, Donovan P, et al. History of childhood maltreatment, negative cognitive styles, and episodes of depression in adulthood. Cognit Ther Res. 2001;25:425-46.

8. van Harmelen A-L, Elzinga BM, Kievit RA, Spinhoven P. Intrusions of autobiographical memories in individuals reporting childhood emotional maltreatment. Eur J Psychotraumatol. 2011;2:7336.

9. Wright MOD, Crawford E, Del Castillo D. Childhood emotional maltreatment and later psychological distress among college students: the mediating role of maladaptive schemas. Child Abus Negl. 2009;33:59-68.

10. Hart SNSN, Binggeli NJ, Brassard MR, Bingelli NJ, Brassard MR. Evidence for the effects of psychological maltreatment. J Emot Abus 1997;1 2013:27-58.

11. Cassels M, van Harmelen A-L, Neufeld S, Goodyer I, Jones PB, Wilkinson P. Poor family functioning mediates the link between childhood adversity and adolescent nonsuicidal self-injury. J Child Psychol Psychiatry Allied Discip. 2018;59(8):881-87

12. van Harmelen A-L, Gibson JL, St Clair MC, Owens M, Brodbeck J, Dunn V, et al. Friendships and family support reduce subsequent depressive symptoms in at-risk adolescents. PLoS One. 2016:11:e0153715.

13. McLaughlin KA, Green JG, Gruber MJ, Sampson NA, Zaslavsky AM, Kessler RC. Childhood adversities and adult psychiatric disorders in the National Comorbidity Survey Replication II. Arch Gen Psychiatry. 2010;67:124.
14. Shaffer A, Yates TM, Egeland BR. The relation of emotional maltreatment to early adolescent competence: developmental processes in a prospective study. Child Abus Negl. 2009;33:36-44.

15. Majer M, Nater UM, Lin J-MS, Capuron L, Reeves WC. Association of childhood trauma with cognitive function in healthy adults: a pilot study. BMC Neurol. 2010;10:61.

16. Savitz JB, van der Merwe L, Stein DJ, Solms M, Ramesar RS. Neuropsychological task performance in bipolar spectrum illness: genetics, alcohol abuse, medication and childhood trauma. Bipolar Disord. 2008;10: 479-94.

17. Kessler RC, Davis CG, Kendler KS. Childhood adversity and adult psychiatric disorder in the US National Comorbidity Survey. Psychol Med. 1997;27:1101-19.

18. Spinhoven P, Elzinga BMM, Hovens JGFMGFM, Roelofs K, Zitman FGG, van Oppen $P$, et al. The specificity of childhood adversities and negative life events across the life span to anxiety and depressive disorders. J Affect Disord. 2010;126:103-12

19. Walsh WA, Dawson J, Mattingly MJ. How are we measuring resilience following childhood maltreatment? Is the research adequate and consistent? What is the impact on research, practice, and policy? Trauma Violence Abuse. 2010;11:27-41.

20. Masten AS. Pathways to integrated resilience science. Psychol Inq. 2015;26: 187-96.

21. Rutter M. Resillencein the face of adversity: protective factors and resistence to psychiatric disorder. Br J Psychiatry. 1985;147:598-611.

22. Kalisch R, Baker DG, Basten U, Boks MP, Bonanno GA, Brummelman E, et al. The resilience framework as a strategy to combat stress-related disorders. Nat Hum Behav. 2017;1(11):784.

23. McEwen BS, Bowles NP, Gray JD, Hill MN, Hunter RG, Karatsoreos IN, et al. Mechanisms of stress in the brain. Nat Neurosci. 2015;18:1353-63.

24. Klika JB, Herrenkohl TI. A review of developmental research on resilience in maltreated children. Trauma Violence Abuse. 2013;14:222-34.

25. Bonanno GA, Wortman CB, Nesse RM. Prospective patterns of resilience and maladjustment during widowhood. Psychol Aging. 2004;19:260-71.

26. Cicchetti D. Annual research review: resilient functioning in maltreated children past, present, and future perspectives. J Child Psychol Psychiatry. 2013;54:402-22.

27. Rutter M. Resilience as a dynamic concept. Dev Psychopathol. 2012;24:335-44.

28. Bowes L, Maughan B, Caspi A, Moffitt TE, Arseneault L. Families promote emotional and behavioural resilience to bullying: evidence of an environmental effect. J Child Psychol Psychiatry. 2010;51:809-17.

29. Sapouna $M$, Wolke $D$. Resilience to bullying victimization: the role of individual, family and peer characteristics. Child Abuse Negl. 2013;37:997-1006.

30. Amstadter AB, Myers JM, Kendler KS. Psychiatric resilience: Iongitudinal twin study. Br J Psychiatry. 2014;205:275-80.

31. Kalisch R, Cramer AOJ, Binder H, Fritz J, Leertouwer I, Lunansky G, et al. Deconstructing and reconstructing resilience: a dynamic network approach. Perspe. 2019; in press:0-20.

32. Masten AS. Global perspectives on resilience in children and youth. Child Dev. 2014;85:6-20

33. Fritz J, de Graaff AM, Caisley H, van Harmelen A-L, Wilkinson PO. A systematic review of amenable resilience factors that moderate and/or mediate the relationship between childhood adversity and mental health in Young people. Front Psychiatry. 2018;9:230. https://doi.org/10.3389/fpsyt. 2018.00230

34. McEwen BS, Gray J, Nasca C. Recognizing resilience: learning from the effects of stress on the brain. Neurobiol Stress. 2015;1:1-11. https://doi.org/ 10.1016/j.ynstr.2014.09.001.

35. Osório C, Probert $\mathrm{T}$, Jones $\mathrm{E}$, Young $A \mathrm{H}$, Robbins I. Adapting to stress: understanding the neurobiology of resilience. Behav Med. 2017;43:307-22 https://doi.org/10.1080/08964289.2016.1170661.

36. Hunter RG, Gray JD, McEwen BS. The neuroscience of resilience. J Soc Social Work Res. 2018;9:305-39. https://doi.org/10.1086/697956.

37. Charney DS. Psychobiological mechanisms of resilience and vulnerability: implications for successful adaptation to extreme stress. Am J Psychiatry. 2004;161:195-216.

38. Agorastos A, Pervanidou P, Chrousos GP, Baker DG. Developmental trajectories of early life stress and trauma: a narrative review on neurobiological aspects beyond stress system Dysregulation. Front psychiatry. 2019;10:118. https://doi.org/10.3389/fpsyt.2019.00118.

39. Feder A, Nestler EJ, Charney DS. Psychobiology and molecular genetics of resilience. Nat Rev Neurosci. 2009:10:446-57. https://doi.org/10.1038/ nrn2649. 
40. Russo SJ, Murrough JW, Han M-H, Charney DS, Nestler EJ. Neurobiology of resilience. Nat Neurosci. 2012;15:1475-84. https://doi.org/10.1038/nn.3234.

41. McEwen BS, Gianaros PJ. Stress- and allostasis-induced brain plasticity. Annu Rev Med. 2011;62:431-45.

42. Miller EK, Cohen JD. An integrative theory of prefrontal cortex function. Annu Rev Neurosci. 2001;24:167-202.

43. Yuan P, Raz N. Prefrontal cortex and executive functions in healthy adults: a meta-analysis of structural neuroimaging studies. Neurosci Biobehav Rev. 2014;42:180-92.

44. Moreno-López L, loannidis K, Askelund AD, Alicia JS, Schueler K, van Harmelen, AL. The resilient emotional brain: a scoping review of mPFC and limbic structure and function in resilient adults with a history of childhood maltreatment. Biol Psychiatry Cogn Neurosci Neuroimaging. 2019. https:// doi.org/10.1016/j.bpsc.2019.12.008.

45. Bolsinger J, Seifritz E, Kleim B, Manoliu A. Neuroimaging correlates of resilience to traumatic events - a comprehensive review. Front Psychiatry. 2018;9:693.

46. Whittle S, Yap MBH, Yücel M, Sheeber L, Simmons JG, Pantelis C, et al. Maternal responses to adolescent positive affect are associated with adolescents' reward neuroanatomy. Soc Cogn Affect Neurosci. 2009;4:247-56.

47. Morey RA, Haswell CC, Hooper SR, De Bellis MD. Amygdala, Hippocampus, and ventral medial prefrontal cortex volumes differ in maltreated youth with and without chronic posttraumatic stress disorder. Neuropsychopharmacology. 2016;41:791-801.

48. Burt KB, Whelan R, Conrod PJ, Banaschewski T, Barker GJ, Bokde ALW, et al. Structural brain correlates of adolescent resilience. J Child Psychol Psychiatry. 2016;57(11):1287-96.

49. Hanson JL, Chung MK, Avants BB, Rudolph KD, Shirtcliff EA, Gee JC, et al. Structural variations in prefrontal cortex mediate the relationship between early childhood stress and spatial working memory. J Neurosci. 2012;32:7917-25.

50. Frodl T, Reinhold E, Koutsouleris N, Donohoe G, Bondy B, Reiser M, et al. Childhood stress, serotonin transporter gene and brain structures in major depression. Neuropsychopharmacology. 2010;35:1383-90.

51. Whittle S, Vijayakumar N, Dennison M, Schwartz O, Simmons JG, Sheeber L, et al. Observed measures of negative parenting predict brain development during adolescence. PLoS One. 2016;11:e0147774.

52. Kievit RA, Davis SW, Mitchell DJ, Taylor JR, Duncan J, Tyler LK, et al. Distinct aspects of frontal lobe structure mediate age-related differences in fluid intelligence and multitasking. Nat Commun. 2014;5:5658.

53. Sheppes G, Suri G, Gross JJ. Emotion regulation and psychopathology. Annu Rev Clin Psychol. 2015;11:379-405. https://doi.org/10.1146/annurev-clinpsy032814-112739.

54. Blair KS, Vythilingam M, Crowe SL, McCaffrey DE, Ng P, Wu CC, et al. Cognitive control of attention is differentially affected in trauma-exposed individuals with and without post-traumatic stress disorder. Psychol Med. 2013;43:85-95.

55. Schweizer S, Walsh ND, Stretton J, Dunn VJ, Goodyer IM, Dalgleish T. Enhanced emotion regulation capacity and its neural substrates in those exposed to moderate childhood adversity. Soc Cogn Affect Neurosci. 2015;11:272-81.

56. Daniels JK, Hegadoren KM, Coupland NJ, Rowe BH, Densmore M, Neufeld RWJ, et al. Neural correlates and predictive power of trait resilience in an acutely traumatized sample: a pilot investigation. J Clin Psychiatry. 2012;73:327-32.

57. DiCorcia JA, Tronick E. Quotidian resilience: exploring mechanisms that drive resilience from a perspective of everyday stress and coping. Neurosci Biobehav Rev. 2011;35:1593-602.

58. Seery MD. Challenge or threat? Cardiovascular indexes of resilience and vulnerability to potential stress in humans. Neurosci Biobehav Rev. 2011;35:1603-10.

59. Arnsten AFT. Stress signalling pathways that impair prefrontal cortex structure and function. Nat Rev Neurosci. 2009;10:410-22.

60. Etkin A, Egner T, Kalisch R. Emotional processing in anterior cingulate and medial prefrontal cortex. Trends Cogn Sci. 2011;15:85-93.

61. Stevens JS, Ely TD, Sawamura T, Guzman D, Bradley B, Ressler KJ, et al. Childhood maltreatment predicts reduced inhibition-related activity in the rostral anterior cingulate in ptsd, but not trauma-exposed controls. Depress Anxiety. 2016;33:614-22.

62. Grimm S, Pestke K, Feeser M, Aust S, Weigand A, Wang J, et al. Early life stress modulates oxytocin effects on limbic system during acute psychosocial stress. Soc Cogn Affect Neurosci. 2014;9:1828-35.

63. Banihashemi L, Sheu LK, Midei AJ, Gianaros PJ. Childhood physical abuse predicts stressor-evoked activity within central visceral control regions. Soc Cogn Affect Neurosci. 2015;10:474-85.

64. Raison $\mathrm{CL}$, Capuron L, Miller AH. Cytokines sing the blues: inflammation and the pathogenesis of depression. Trends Immunol. 2006;27:24-31.
65. McEwen BS. Protective and damaging effects of stress mediators. N Engl J Med. 1998;338:171-9.

66. Fries E, Hesse J, Hellhammer J, Hellhammer DH. A new view on hypocortisolism. Psychoneuroendocrinology. 2005;30:1010-6.

67. Goldstein DS, McEwen B. Allostasis, homeostats, and the nature of stress. Stress. 2002;5:55-8.

68. Heim C, Ehlert U, Hellhammer DH. The potential role of hypocortisolism in the pathophysiology of stress-related bodily disorders.

Psychoneuroendocrinology. 2000;25:1-35.

69. Susman EJ. Psychobiology of persistent antisocial behavior: stress, early vulnerabilities and the attenuation hypothesis. Neurosci Biobehav Rev. 2006; 30:376-89.

70. De Bellis MD, Keshavan MS, Clark DB, Casey BJ, Giedd JN, Boring AM, et al. Developmental traumatology part II: brain development*. Biol Psychiatry. 1999:45:1271-84.

71. Gunnar MR, Vazquez DM. Low cortisol and a flattening of expected daytime rhythm: potential indices of risk in human development. Dev Psychopathol. 2001;13:515-38.

72. Carlson M, Earls F. Psychological and neuroendocrinological sequelae of early social deprivation in institutionalized children in Romania. Ann N Y Acad Sci. 1997;807:419-28.

73. Khoury JE, Bosquet Enlow M, Plamondon A, Lyons-Ruth K. The association between adversity and hair cortisol levels in humans: a meta-analysis. Psychoneuroendocrinology. 2019;103:104-17.

74. Koss KJ, Gunnar MR. Annual research review: early adversity, the hypothalamic-pituitary-adrenocortical axis, and child psychopathology. J Child Psychol Psychiatry. 2018;59:327-46.

75. Bunea IM, Szentágotai-Tătar A, Miu AC. Early-life adversity and cortisol response to social stress: a meta-analysis. Transl Psychiatry. 2017;7:1274.

76. Fogelman N, Canli T. Early life stress and cortisol: a meta-analysis. Horm Behav. 2018;98:63-76.

77. Goodyer IM, Herbert J, Tamplin A, Altham PM. Recent life events, cortisol, dehydroepiandrosterone and the onset of major depression in high-risk adolescents. Br J Psychiatry. 2000;177:499-504.

78. Cicchetti D, Rogosch FA. Personality, adrenal steroid hormones, and resilience in maltreated children: a multilevel perspective. Dev Psychopathol 2007;19:787-809.

79. Goodyer IM, Herbert J, Altham PM. Adrenal steroid secretion and major depression in 8- to 16-year-olds, III. Influence of cortisol/DHEA ratio at presentation on subsequent rates of disappointing life events and persistent major depression. Psychol Med. 1998;28:265-73.

80. Goodyer IM, Park RJ, Netherton CM, Herbert J. Possible role of cortisol and dehydroepiandrosterone in human development and psychopathology. $\mathrm{Br}$ Psychiatry. 2001;179:243-9.

81. Mazur A, Booth A. Testosterone and dominance in men. Behav Brain Sci. 1998;21:353-63 discussion 363-97.

82. Frost CP, Meyerand ME, Birn RM, Hoks RM, Walsh EC, Abercrombie HC. Childhood emotional abuse moderates associations among Corticomotor white matter structure and stress neuromodulators in women with and without depression. Front Neurosci. 2018;12:256

83. Dahmen B, Puetz VB, Scharke W, von Polier GG, Herpertz-Dahlmann B, Konrad K. Effects of early-life adversity on hippocampal structures and associated HPA Axis functions. Dev Neurosci. 2018;40:13-22.

84. Höschl C, Hajek T. Hippocampal damage mediated by corticosteroids - a neuropsychiatric research challenge. Eur Arch Psychiatry Clin Neurosci. 2001;251:81-8.

85. Uno H, Tarara R, Else JG, Suleman MA, Sapolsky RM. Hippocampal damage associated with prolonged and fatal stress in primates. J Neurosci. 1989;9:1705-11.

86. Frodl T, O'Keane V. How does the brain deal with cumulative stress? A review with focus on developmental stress, HPA axis function and hippocampal structure in humans. Neurobiol Dis. 2013;52:24-37.

87. Paluš M, Krakovská A, Jakubík J, Chvosteková M. Causality, dynamical systems and the arrow of time. Chaos An Interdiscip J Nonlinear Sci. 2018; 28:075307.

88. Pongratz $\mathrm{G}$, Straub $\mathrm{RH}$. The sympathetic nervous response in inflammation. Arthritis Res Ther. 2014;16:504.

89. Danese A, Baldwin JR. Hidden Wounds? Inflammatory Links Between Childhood Trauma and Psychopathology. Annu Rev Psychol. 2017;68: annurev-psych-010416-044208.

90. Miller $\mathrm{AH}$, Raison $\mathrm{CL}$. The role of inflammation in depression: from evolutionary imperative to modern treatment target. Nat Rev Immunol. 2016;16:22-34. 
91. Miller GE, Chen E. Harsh family climate in early life presages the emergence of a proinflammatory phenotype in adolescence. Psychol Sci. 2010;21:848-56.

92. Raison $\mathrm{CL}$, Miller $\mathrm{AH}$. When not enough is too much: the role of insufficient glucocorticoid signaling in the pathophysiology of stress-related disorders. Am J Psychiatry. 2003;160:1554-65.

93. Danese A, McEwen BS. Adverse childhood experiences, allostasis, allostatic load, and age-related disease. Physiol Behav. 2012;106:29-39.

94. Silverman MN, Sternberg EM. Glucocorticoid regulation of inflammation and its functional correlates: from HPA axis to glucocorticoid receptor dysfunction. Ann N Y Acad Sci. 2012;1261:55-63.

95. Barnes PJ, Adcock IM. Glucocorticoid resistance in inflammatory diseases. Lancet (London, England). 2009;373:1905-17.

96. Cicchetti D, Handley ED, Rogosch FA. Child maltreatment, inflammation, and internalizing symptoms: investigating the roles of C-reactive protein, gene variation, and neuroendocrine regulation. Dev Psychopathol. 2015;27:553-66.

97. Danese A, Tan M. Childhood maltreatment and obesity: systematic review and meta-analysis. Mol Psychiatry. 2014;19:544-54.

98. Danese A, Moffitt TE, Harrington H, Milne BJ, Polanczyk G, Pariante CM, et al. Adverse childhood experiences and adult risk factors for age-related disease: depression, inflammation, and clustering of metabolic risk markers. Arch Pediatr Adolesc Med. 2009:163:1135-43.

99. Danese A, Pariante CM, Caspi A, Taylor A, Poulton R. Childhood maltreatment predicts adult inflammation in a life-course study. Proc Natl Acad Sci U S A. 2007;104:1319-24.

100. McEwen BS. Glucocorticoids, depression, and mood disorders: structural remodeling in the brain. Metabolism. 2005;54(5 Suppl 1):20-3.

101. Hostinar CE, Davidson RJ, Graham EK, Mroczek DK, Lachman ME, Seeman $\mathrm{TE}$, et al. Frontal brain asymmetry, childhood maltreatment, and low-grade inflammation at midlife. Psychoneuroendocrinology. 2017;75:152-63.

102. Danese A, van Harmelen A-L. The hidden wounds of childhood trauma. Invited editorial. Eur J Psychotraumatol. 2017; In press.

103. Dargél AA, Godin O, Kapczinski F, Kupfer DJ, Leboyer M. C-reactive protein alterations in bipolar disorder: a meta-analysis. J Clin Psychiatry. 2015;76:142-50.

104. Eraly SA, Nievergelt CM, Maihofer AX, Barkauskas DA, Biswas N, Agorastos A, et al. Assessment of plasma C-reactive protein as a biomarker of posttraumatic stress disorder risk. JAMA psychiatry. 2014:71:423-31.

105. Howren MB, Lamkin DM, Suls J. Associations of depression with C-reactive protein, IL-1, and IL-6: a meta-analysis. Psychosom Med. 2009;71:171-86.

106. Matthews KA, Schott LL, Bromberger JT, Cyranowski JM, Everson-Rose SA, Sowers M. Are there bi-directional associations between depressive symptoms and C-reactive protein in mid-life women? Brain Behav Immun. 2010;24:96-101.

107. Modabbernia A, Taslimi S, Brietzke E, Ashrafi M. Cytokine alterations in bipolar disorder: a meta-analysis of 30 studies. Biol Psychiatry. 2013;74:15-25.

108. Solmi M, Veronese N, Favaro A, Santonastaso P, Manzato E, Sergi G, et al. Inflammatory cytokines and anorexia nervosa: a meta-analysis of crosssectional and longitudinal studies. Psychoneuroendocrinology. 2015;51:237-52.

109. Strawbridge R, Arnone D, Danese A, Papadopoulos A, Herane Vives A, Cleare AJ. Inflammation and clinical response to treatment in depression: a meta-analysis. Eur Neuropsychopharmacol. 2015;25:1532-43.

110. Gururajan A, van de Wouw M, Boehme M, Becker T, O'Connor R, Bastiaanssen TFS, et al. Resilience to chronic stress is associated with specific neurobiological, neuroendocrine and immune responses. Brain Behav Immun. 2019. https://doi.org/10.1016/j.bbi.2019.05.004.

111. Cicchetti D, Rogosch FA. Gene by environment interaction and resilience: effects of child maltreatment and serotonin, Corticotropin releasing hormone, dopamine, and Oxyctocin genes. Dev Psychopathol. 2012;24:411-27.

112. Lupien SJ, McEwen BS, Gunnar MR, Heim C. Effects of stress throughout the lifespan on the brain, behaviour and cognition. Nat Rev Neurosci. 2009;10:434-45.

113. Carballedo A, Morris D, Zill P, Fahey C, Reinhold E, Meisenzahl E, et al. Brainderived neurotrophic factor $\{\{\}$ Val\{\}\}66Met polymorphism and early life adversity affect hippocampal volume. Am J Med Genet Part BNeuropsychiatric Genet. 2013;162B:183-90

114. Frodl T, Skokauskas N, Frey E-M, Morris D, Gill M, Carballedo A. BDNFVal66Met genotype interacts with childhood adversity and influences the formation of hippocampal subfields. Hum Brain Mapp. 2014;35:5776-83.

115. Molendijk ML, Bus BAA, Spinhoven P, Kaimatzoglou A, Voshaar RCO, Penninx BWJH, et al. A systematic review and meta-analysis on the association between BDNF val66met and hippocampal volume-a genuine effect or a winners curse? Am J Med Genet Part B Neuropsychiatr Genet. 2012;159B:731-40
116. van Velzen LS, Schmaal L, Jansen R, Milaneschi Y, Opmeer EM, Elzinga BM, et al. Effect of childhood maltreatment and brain-derived neurotrophic factor on brain morphology. Soc Cogn Affect Neurosci. 2016;11:1841-52.

117. Walsh ND, Dalgleish T, Dunn VJ, Abbott R, St Clair MC, Owens M, et al. 5HTTLPR-environment interplay and its effects on neural reactivity in adolescents. Neuroimage. 2012;63:1670-80.

118. Opmeer EEM, Kortekaas R, van Tol M-J, van der Wee NJA, Woudstra S, van Buchem MA, et al. Interaction of neuropeptide $Y$ genotype and childhood emotional maltreatment on brain activity during emotional processing. Soc Cogn Affect Neurosci. 2013;9(5):601-9.

119. Caspi A, McClay J, Moffitt TE, Mill J, Martin J, Craig IW, et al. Role of genotype in the cycle of violence in maltreated children. Science. 2002;297:851-4.

120. Kim-Cohen J, Caspi A, Taylor A, Williams B, Newcombe R, Craig IW, et al. MAOA, maltreatment, and gene-environment interaction predicting children's mental health: new evidence and a meta-analysis. Mol Psychiatry. 2006;11:903-13.

121. Weder N, Yang BZ, Douglas-Palumberi H, Massey J, Krystal JH, Gelernter J, et al. MAOA genotype, maltreatment, and aggressive behavior: the changing impact of genotype at varying levels of trauma. Biol Psychiatry. 2009;65:417-24.

122. Klengel T, Mehta D, Anacker C, Rex-Haffner M, Pruessner JC, Pariante CM, et al. Allele-specific FKBP5 DNA demethylation mediates gene-childhood trauma interactions. Nat Neurosci. 2013;16:33-41.

123. Duncan L, Keller M. A critical review of the first 10 years of candidate gene-byenvironmental interaction research in psychiatry. Am J Psychiatry. 2011;168:1041-9.

124. Culverhouse RC, Saccone NL, Horton AC, Ma Y, Anstey KJ, Banaschewski T, et al. Collaborative meta-analysis finds no evidence of a strong interaction between stress and 5-HTTLPR genotype contributing to the development of depression. Mol Psychiatry. 2017;23(1):133.

125. Border R, Johnson EC, Evans LM, Smolen A, Berley N, Sullivan PF, et al. No support for historical candidate gene or candidate gene-by-interaction hypotheses for major depression across multiple large samples. Am J Psychiatry. 2019;176:376-87.

126. Halldorsdottir T, Binder EB. Gene $\times$ environment interactions: from molecular mechanisms to behavior. Annu Rev Psychol. 2017;68:215-41.

127. Sullivan PF, Daly MJ, O'Donovan M. Genetic architectures of psychiatric disorders: the emerging picture and its implications. Nat Rev Genet. 2012;13:537-51.

128. Pezawas L, Meyer-Lindenberg A, Goldman AL, Verchinski BA, Chen G, Kolachana BS, et al. Evidence of biologic epistasis between BDNF and SLC6A4 and implications for depression. Mol Psychiatry. 2008;13:709-16.

129. Hammen C, Brennan PA, Le Brocque R. Youth depression and early childrearing: stress generation and intergenerational transmission of depression. J Consult Clin Psychol. 2011;79:353-63.

130. Chambers CD, Dienes Z, Mclntosh RD, Rotshtein P, Willmes K. Registered reports: realigning incentives in scientific publishing. Cortex. 2015;66:A1-2.

131. Brown DL, Tylka TL. Racial discrimination and resilience in African American Young adults: examining racial socialization as a moderator. J Black Psychol. 2011:37:259-85.

132. Carranza ME. Building resilience and resistance against racism and discrimination among Salvadorian female youth in Canada. Child Fam Soc Work. 2007;12:390-8

133. Dang MT. Social connectedness and self-esteem: predictors of resilience in mental health among maltreated homeless youth. Issues Ment Health Nurs. 2014;35:212-9.

134. Cicchetti D, Lynch M. Failures in the expectable environment and their impact on individual development: the case of child maltreatment: risk, disorder, and adaptation; 1995.

135. Luthar SS. Resilience in development: a synthesis of research across five decades. In: Developmental psychopathology: risk, disorder, and adaptation, Vol. 3. 2nd ed. Hoboken: Wiley; 2006. p. 739-95.

136. Gartland D, Riggs E, Muyeen S, Giallo R, Afifi TO, Macmillan H, et al. What factors are associated with resilient outcomes in children exposed to social adversity? A systematic review. BMJ Open. 2019;9.

137. Ungar M, Ghazinour M, Richter J. Annual Research Review: What is resilience within the social ecology of human development? J Child Psychol Psychiatry. 2013;54(4):348-66.

138. Ungar M. Systemic resilience: principles and processes for a science of change in contexts of adversity. Ecol Soc. 2018;23.

139. van Harmelen A-L, Kievit RA, loannidis $K$, Neufeld $S$, Jones PB, Bullmore E, et al. Adolescent friendships predict later resilient functioning across psychosocial domains in a healthy community cohort. Psychol Med. 2017; 47:2312-22. 
140. Laviola G, Rea M, Morley-Fletcher S, Di Carlo S, Bacosi A, De Simone R, et al. Beneficial effects of enriched environment on adolescent rats from stressed pregnancies. Eur J Neurosci. 2004;20:1655-64.

141. Mora F, Segovia G, del Arco A. Aging, plasticity and environmental enrichment: structural changes and neurotransmitter dynamics in several areas of the brain. Brain Res Rev. 2007;55:78-88.

142. Morley-Fletcher S, Rea M, Maccari S, Laviola G, Regina V, Roma I. Environmental enrichment during adolescence reverses the effects of prenatal stress on play behaviour and HPA axis reactivity in rats. Eur J Neurosci. 2003;18:3367-74.

143. Sachser N, Hennessy MB, Kaiser S. Adaptive modulation of behavioural profiles by social stress during early phases of life and adolescence. Neurosci Biobehav Rev. 2011;35:1518-33.

144. Eisenberger NI, Taylor SE, Gable SL, Hilmert CJ, Lieberman MD. Neural pathways link social support to attenuated neuroendocrine stress responses. Neuroimage. 2007;35:1601-12.

145. Masten $\mathrm{CL}$, Telzer EH, Fuligni AJ, Lieberman MD, Eisenberger NI. Time spent with friends in adolescence relates to less neural sensitivity to later peer rejection. Soc Cogn Affect Neurosci. 2012;7:106-14

146. Muscatell KA, Dedovic K, Slavich GM, Jarcho MR, Breen EC, Bower JE, et al. Neural mechanisms linking social status and inflammatory responses to social stress. Soc Cogn Affect Neurosci. 2016;11:915-22.

147. Williams KD, Jarvis B. Cyberball: a program for use in research on interpersonal ostracism and acceptance. Behav Res Methods. 2006;38: 174-80.

148. Olsavsky AK, Telzer EH, Shapiro M, Humphreys KL, Flannery J, Goff B, et al. Indiscriminate amygdala response to mothers and strangers after early maternal deprivation. Biol Psychiatry. 2013;74:853-60.

149. Bick J, Zhu T, Stamoulis C, Fox NA, Zeanah C, Nelson CA. Effect of early institutionalization and Foster Care on long-term white matter development. JAMA Pediatr. 2015;169:211

150. Bronfenbrenner U. The ecology of human development. Cambridge: Harvard University Press; 1979.

151. Bhugra D, Becker MA. Migration, cultural bereavement and cultural identity. World Psychiatry. 2005;4:18-24.

152. Murphy HBM. Migration, culture and mental health. Psychol Med. 1977;7: 677-84.

153. Kreek MJ. Extreme marginalization: addiction and other mental health disorders, stigma, and imprisonment. Ann N Y Acad Sci. 2011;1231:65-72.

154. Kirmayer $L$, Brass GM, Tait $C L$. The mental health of aboriginal peoples: transformations of identity and community. Can J Psychiatr. 2000;45:607-16.

155. Panter-Brick C, Hadfield K, Dajani R, Eggerman M, Ager A, Ungar M. Resilience in context: a brief and culturally grounded measure for Syrian refugee and Jordanian host-community adolescents. Child Dev. 2018;89:1803-20.

156. Beiser M. Resettling refugees and safeguarding their mental health: lessons learned from the Canadian refugee resettlement project. Transcult Psychiatry. 2009;46:539-83.

157. Klasen F, Oettingen G, Daniels J, Post M, Hoyer C, Adam H. Posttraumatic resilience in former Ugandan child soldiers. Child Dev. 2010;81:1096-113.

158. Masten AS. Resilience theory and research on children and families: past, present, and promise. J Fam Theory Rev. 2018;10:12-31.

159. Ford DH, Lerner RM. Developmental systems theory : an integrative approach. Newbury Park: Sage Publications; 1992.

160. Rickles D, Hawe P, Shiell A. A simple guide to chaos and complexity. J Epidemiol Community Health. 2007;61:933-7. https://doi.org/10.1136/jech.2006.054254.

161. Kalisch R, Cramer AOJ, Binder H, Fritz J, Leertouwer I, Lunansky G, et al. Deconstructing and reconstructing resilience: a dynamic network approach. 2019; May:0-20.

162. Masten AS, Barnes AJ. Resilience in Children: Developmental Perspectives. Child (Basel, Switzerland). 2018;5. doi:https://doi.org/10.3390/ children5070098.

163. Muller D, Judd CM, Yzerbyt WY. When moderation is mediated and mediation is moderated. J Pers Soc Psychol. 2005;89:852-63.

164. Hayes AF. Introduction to mediation, moderation, and conditional process analysis: a regression-based approach. 2nd ed. New York: Guilford Press; 2018

165. Askelund AD, Schweizer S, Goodyer IM, van Harmelen A-L. Positive memory specificity is associated with reduced vulnerability to depression. Nat Hum Behav. 2019;3(3):265.

166. Maccallum F, Galatzer-Levy IR, Bonanno GA. Trajectories of depression following spousal and child bereavement: a comparison of the heterogeneity in outcomes. J Psychiatr Res. 2015;69:72-9.
167. Bystritsky A, Nierenberg AA, Feusner JD, Rabinovich M. Computational nonlinear dynamical psychiatry: a new methodological paradigm for diagnosis and course of illness. J Psychiatr Res. 2012;46:428-35.

168. Richardson M, Dale R, research KM-H of, 2014 undefined. Complex dynamical systems in social and personality psychology 2014.

169. Wichers M, Schreuder MJ, Goekoop R, Groen RN. Can we predict the direction of sudden shifts in symptoms? Transdiagnostic implications from a complex systems perspective on psychopathology. Psychol Med. 2019;49:380-7.

170. Hofmann SG, Curtiss J, McNally RJ. A complex network perspective on clinical science. Perspect Psychol Sci. 2016;11:597-605.

171. De Domenico M, Brockmann D, Camargo C, Gershenson C, Goldsmith D, Jeschonnek S, et al. Complexity Explained. https://complexityexplained. github.io. Accessed 22 Nov 2019.

172. Kline RB. Principles and practice of structural equation modeling. 3rd ed. New York: Guilford Press; 2011.

173. Kievit RA, Davis SW, Griffiths J, Correia MM, Cam-CAN, Henson RN. A watershed model of individual differences in fluid intelligence Neuropsychologia 2016:91:186-198.

174. Duncan TE, Duncan SC, Strycker LA, Duncan SC, Strycker LA. An Introduction to Latent Variable Growth Curve Modeling. New York: Routledge; 2013.

175. de Roon-Cassini TA, Mancini AD, Rusch MD, Bonanno GA. Psychopathology and Resilience Following Traumatic Injury: A Latent Growth Mixture Model Analysis. Rehabil Psychol. 2010;55:1-11.

176. Borsboom D, Cramer AOJ. Network analysis: an integrative approach to the structure of psychopathology. Annu Rev Clin Psychol. 2013;9:91-121.

177. Epskamp S, Rhemtulla M, Borsboom D. Generalized network psychometrics: combining network and latent variable models. Psychometrika. 2017;82:904-27.

178. Fritz J, Fried El, Goodyer IM, Wilkinson PO, van Harmelen A-L. A network model of resilience factors for adolescents with and without exposure to childhood adversity. Sci Rep. 2018;8:15774.

179. Scheffer M, Bolhuis JE, Borsboom D, Buchman TG, Gijzel SMW, Goulson D, et al. Quantifying resilience of humans and other animals. Proc Natl Acad Sci. 2018;115:11883-90.

180. Fried El, Haslbeck JM. Using network analysis to examine links between individual depressive symptoms, inflammatory markers, and covariates. Psychol Med. 2019;1-9.

181. Ungar M. The social ecology of resilience: addressing contextual and cultural ambiguity of a nascent construct. Am J Orthop. 2011;81:1-17.

182. Masten AS, Cicchetti D. Resilience in development: Progress and transformation. In: Developmental psychopathology. Hoboken: Wiley; 2016. p. 1-63.

183. Finn DP, Viveros M-P, Marco EM. The endocannabinoid system and emotional processing: pathophysiology and therapeutic potential. J Psychopharmacol. 2012;26:3-6.

184. McCrory EJ, Viding E. The theory of latent vulnerability: Reconceptualizing the link between childhood maltreatment and psychiatric disorder. Dev Psychopathol. 2015;27:493-505.

185. Teicher MH, Samson JA. Annual research review: enduring neurobiological effects of childhood abuse and neglect. J Child Psychol Psychiatry. 2016;57: 241-66

186. Luthar SS, Cicchetti D, Becker B. The construct of resilience: a critical evaluation and guidelines for future work. Child Dev. 2015;71:543-62.

187. Masten AS, Narayan AJ. Child development in the context of disaster, war, and terrorism: pathways of risk and resilience. Annu Rev Psychol. 2012;63: 227-57.

188. Bonanno GA, Romero SA, Klein SI. The temporal elements of psychological resilience: an integrative framework for the study of individuals, families, and communities. Psychol Inq. 2015;26:139-69.

189. Green BL, Goodman LA, Krupnick JL, Corcoran CB, Petty RM, Stockton P, et al. Outcomes of single versus multiple trauma exposure in a screening sample. J Trauma Stress. 2000;13:271-86.

190. Brewin CR, Cloitre M, Hyland P, Shevlin M, Maercker A, Bryant RA, et al. A review of current evidence regarding the ICD-11 proposals for diagnosing PTSD and complex PTSD. Clin Psychol Rev. 2017:58:1-15.

191. Brewin CR. Complex post-traumatic stress disorder: a new diagnosis in ICD11. BJPsych Adv. 2019:1-8.

192. Maung HH. Diagnosis and causal explanation in psychiatry. Stud Hist Philos Sci Part C Stud Hist Philos Biol Biomed Sci. 2016;60:15-24.

193. McLaughlin KA, Sheridan MA, Lambert HK. Childhood adversity and neural development: deprivation and threat as distinct dimensions of early experience. Neurosci Biobehav Rev. 2014;47:578-91. 
194. Lupien SJ, Ouellet-Morin I, Herba CM, Juster R, McEwen BS. From vulnerability to neurotoxicity: a developmental approach to the effects of stress on the brain and behavior. In: Spengler D, Binder E, editors. Epigenetics and neuroendocrinology: clinical focus on psychiatry, Volume 1. Cham: Springer International Publishing; 2016. p. 3-48.

195. Khan A, McCormack HC, Bolger EA, McGreenery CE, Vitaliano G, Polcari A, et al. Childhood maltreatment, depression, and suicidal ideation: critical importance of parental and peer emotional abuse during developmental sensitive periods in males and females. Front Psychiatry. 2015;6:42.

196. Slopen N, Kubzansky LD, McLaughlin KA, Koenen KC. Childhood adversity and inflammatory processes in youth: a prospective study. Psychoneuroendocrinology. 2013;38:188-200.

197. Harpur LJ, Polek E, van Harmelen AL. The role of timing of maltreatment and child intelligence in pathways to low symptoms of depression and anxiety in adolescence. Child Abus Negl. 2015:47:24-37.

198. Seery MD, Holman EA, Silver RC. Whatever does not kill us: cumulative lifetime adversity, vulnerability, and resilience. J Pers Soc Psychol. 2010;99: 1025-41. https://doi.org/10.1037/a0021344.

199. Rutter M. Psychosocial resilience and protective mechanisms. Am J Orthop. 1987;57:316-31

200. Dang R, Guo Y, Zhang K, Jiang P, Zhao M. Predictable chronic mild stress promotes recovery from LPS-induced depression. Mol Brain. 2019;12:42. https://doi.org/10.1186/s13041-019-0463-2.

201. Oldehinkel AJ, Ormel J, Verhulst FC, Nederhof E. Childhood adversities and adolescent depression: A matter of both risk and resilience. Dev Psychopathol. 2014:26(4pt1):1067-75.

202. Catalani A, Alemà GS, Cinque C, Zuena AR, Casolini P. Maternal corticosterone effects on hypothalamus-pituitary-adrenal axis regulation and behavior of the offspring in rodents. Neurosci Biobehav Rev. 2011;35:1502-17.

203. Macrì S, Zoratto F, Laviola G. Early-stress regulates resilience, vulnerability and experimental validity in laboratory rodents through mother-offspring hormonal transfer. Neurosci Biobehav Rev. 2011;35:1534-43.

204. Del Giudice M, Ellis BJ, Shirtcliff EA. The adaptive calibration model of stress responsivity. Neurosci Biobehav Rev. 2011;35:1562-92.

205. Sih A. Effects of early stress on behavioral syndromes: an integrated adaptive perspective. Neurosci Biobehav Rev. 2011;35:1452-65.

206. Masten AS, Garmezy N. Risk, vulnerability, and protective factors in developmental psychopathology. New York: Plenum Press; 1985.

207. Rutter M. Resilience: some conceptual considerations. J Adolesc Health. 1993;14:626-31 690-6.

208. Blackwell SE, Rius-Ottenheim N, Schulte-van Maaren YWM, Carlier IVE, Middelkoop VD, Zitman FG, et al. Optimism and mental imagery: a possible cognitive marker to promote well-being? Psychiatry Res. 2013;206:56-61.

209. Mak WWS, Ng ISW, Wong CCY. Resilience: enhancing well-being through the positive cognitive triad. J Couns Psychol. 2011;58:610-7.

210. Lumley MN, McArthur BA. Protection From Depression Following Emotional Maltreatment: The Unique Role of Positive Schemas. Int I Cogn Ther. 2016; 9(4):327-43.

211. Cicchetti D. Resilience under conditions of extreme stress: a multilevel perspective. World Psychiatry. 2010;9:145-54.

\section{Publisher's Note}

Springer Nature remains neutral with regard to jurisdictional claims in published maps and institutional affiliations.

\section{Ready to submit your research? Choose BMC and benefit from:}

- fast, convenient online submission

- thorough peer review by experienced researchers in your field

- rapid publication on acceptance

- support for research data, including large and complex data types

- gold Open Access which fosters wider collaboration and increased citations

- maximum visibility for your research: over $100 \mathrm{M}$ website views per year

At $\mathrm{BMC}$, research is always in progress.

Learn more biomedcentral.com/submissions 